The Egyptian Journal of Hospital Medicine (October 2018) Vol. 73 (8), Page 7258-7261

\title{
Effect of Indirect Biliary Cannulation on Endoscopic Retrograde Cholangiopancreatography Outcome
}

\author{
Mohamed Abdelrasheed Allam, Mahmoud Abdelrasheed Allam, Emad Ads \\ Tropical Medicine Departments, Internal Medicine Departments, General surgery department, Al-Azhar \\ University
}

\begin{abstract}
:
Background and aim: - Variable techniques could be used to raise the success rate and reduce complications of endoscopic retrograde cholangiopancreatography (ERCP).

We aimed to evaluate the effect of indirect biliary cannulation techniques as double guide-wire technique (DGT), trans-pancreatic sphincterotomy (TPS) andlor temporary pancreatic stenting on ERCP procedure outcome.

Patients and methods: - From 73 patients subjected to ERCP in our endoscopy unit, during the period between January 2016 to December 2017, 47 patients were managed with standard free direct cannulation maneuver (groupI), 21 patients managed with indirect maneuvers (DGT andlor TPS as group-II) and ERCP was failed in 5 cases; in 3 of them temporary pancreatic stent was placed but with no value.

Results: - From 73 patients, standard free direct cannulation was done in 47 patients with success rate $64.4 \%$, the remaining 26 patients managed with indirect maneuvers with successful cannulation of CBD in 21 cases with success rate $80.7 \%$ and total success rate of $94.4 \%$.

Procedure duration was longer in patients of indirect maneuvers than patients of standard free direct cannulation maneuver, with high significant difference ( $\mathrm{P}$ value of 0.0036 ).

The post-ERCP complications were noticed in 21 patients with complications rate of $28.8 \%$. Complications were significantly higher in patients of indirect maneuvers than patients of standard direct maneuver (47.6\% vs. $23.4 \%$ ). Post-ERCP pancreatitis recorded in 7 patients $(9.6 \%)$ with significant higher rate in patients of indirect maneuvers than patients of direct maneuver $(23.8 \%$ vs. $4.3 \%)$.

Conclusion: - Indirect biliary cannulation (DGT and/or TPS) solved the problem of failed cannulation but had a higher rate of complications and took longer time.
\end{abstract}

Keyword: - ERCP; endoscopic retrograde cholangiopancreatography, Indirect ERCP maneuvers.

\section{Introduction: -}

Successful biliary cannulation is a crucial step for endoscopic retrograde cholangiopancreatography $(\mathrm{ERCP})^{1}$. Experienced endoscopists should achieve successful biliary cannulation rates more than $90 \%{ }^{2}$. Some factors as altered anatomy, inflamed tissues and adenomatous papilla or periampullary diverticulum may increase the bile duct (BD) cannulation difficulties ${ }^{3}$.

Altered endoscopic techniques were developed in the past few years to increase the success rate of cannulation ${ }^{4}$.

Double-guidewire technique (DGT) is the use of a guidewire to occupy the pancreatic duct (PD) ${ }^{\mathbf{5}}$. Double-guidewire technique has been used with promising results in cases of failed cannulation ${ }^{5}$.

Alternative techniques for difficult cannulation is transpancreatic sphincterotomy (TPS) in which sphincterotomy cut in the PD to help biliary cannulation andlor temporary pancreatic stenting; it could be explained as the cut either opens the BD or exposes the duct's anatomy ${ }^{6}$.

Double-guidewire technique and TPS might facilitate biliary cannulation. However, with DGT and TPS post-ERCP pancreatitis was reported in $0 \%$ to $25 \%$ of patients ${ }^{3}$.

Objective: - We aimed to evaluate the effect of indirect biliary cannulation techniques as double guide-wire technique (DGT), trans-pancreatic sphincterotomy (TPS) andlor temporary pancreatic stenting regarding procedure duration, success and complications.

Patients and methods: -

This prospective study was carried out at Al-Hussein University Hospitals ERCP Unit, during the between January 2016 to December 2017, on 89 cases of ERCP. The study was approved by the Ethics Board of Al-Azhar University. 
Sixteen patients with history of pancreatico-biliary surgery, not cholecystectomy, previous ERCP, duodenal obstruction or acute pancreatitis were excluded.

The remaining 73 patients were classified according to the procedure progress, as 47 cases of standard free direct biliary cannulation (as group-I), 21 cases of difficult cannulation in whom indirect maneuvers were done (as group-II) and 5 cases of failed ERCP.

For all patient clear written consent, full clinical and routine laboratory assessment and abdominal sonography were done and ERCP was performed in the standard manner using a side-view endoscope (Fujinon ED-250 XT Duodenoscope). After cannulation of the CBD, an initial cholangiogram was taken.

All patients were monitored at least for 24 hours after the procedure to detect symptoms and signs of complications (e.g. tachycardia, hypotension, fever, vomiting andlor abdominal pain). Serum amylase was done four hours post-ERCP. Patients were then either hospitalized or followed up by phone contact. $\chi^{2}$-test of significance and F-test of the equality of two variances were used to compare proportions between two qualitative parameters. Probability (P value) was considered significant if less than 0.05 .

Results: - A total of 89 patients with obstructive jaundice were included in this study, 16 cases were excluded because of previous pancreatico-biliary surgery or ERCP procedure.

The remaining 73 patients divided according to the procedure done as; group I consisted of 47 cases managed with standard direct free cannulation maneuver and 21 cases managed with indirect maneuvers. The procedure was failed in 5 cases; 3 cases of duodenal mass, one case of hidden papilla and one case of flat tiny papilla.

There was no significant difference between the studied groups regarding age and sex distribution, clinical presentation, laboratory findings and sonographic findings.

Procedure duration was longer in patients of indirect maneuvers than patients of standard direct free cannulation maneuver, with high significant difference (P value of 0.0036) (table 1)

\section{Statistical analysis: -}

Table 1: - Procedure findings and maneuver done in each group

\begin{tabular}{|c|c|c|c|c|}
\hline 68 cases of succeed ERCP & $\begin{array}{l}\text { Gp-I } \\
(\mathrm{n}: 47)\end{array}$ & $\begin{array}{l}\text { Gp-II } \\
(n: 21)\end{array}$ & $\mathbf{X}^{2}$ & $\mathbf{P}$ \\
\hline \multicolumn{5}{|l|}{ Duration of procedure } \\
\hline$<30$ min. & $30(63.8 \%)$ & $5(23.8 \%)$ & & \\
\hline 30-60 min. & $14(29.8 \%)$ & $10(47.6 \%)$ & 11.2234 & $* 0.0036$ \\
\hline$>60 \mathrm{~min}$. & $3(6.3 \%)$ & $6(28.6 \%)$ & & \\
\hline peri-papillary diverticulum & $2(4.3 \%)$ & $1(4.8 \%)$ & 0.008 & 0.9251 \\
\hline Papillary swelling & $3(6.3 \%)$ & $3(14.3 \%)$ & 1.126 & 0.2884 \\
\hline Duodenal mass & $1(2.1 \%)$ & $1(4.8 \%)$ & 0.352 & 0.5525 \\
\hline Calcular $(52=71.2 \%)$ & $41(87.2 \%)$ & $11(52.3 \%)$ & \multirow{4}{*}{2.1671} & \multirow{4}{*}{0.3383} \\
\hline $\begin{array}{l}\text { - Stone extraction without } \\
\text { lithotriptor use }\end{array}$ & $35(74.5 \%)$ & $8(38 \%)$ & & \\
\hline - Lithotriptor use & $4(8.5 \%)$ & $1(4.8 \%)$ & & \\
\hline - Stent placement & $2(4.2 \%)$ & $2(9.5 \%)$ & & \\
\hline Neoplastic (12) & $\mathbf{4}(8.5 \%)$ & $8(38 \%)$ & \multirow{3}{*}{0.300} & \multirow{3}{*}{0.5838} \\
\hline - Stent placement & $3(6.4 \%)$ & $7(33.3 \%)$ & & \\
\hline $\begin{array}{l}\text { - Baloon dilation followed with } \\
\text { stent }\end{array}$ & $1(2.1 \%)$ & $1(4.8 \%)$ & & \\
\hline Stricture (2) & $1(2.1 \%)$ & $1(4.8 \%)$ & \multirow{3}{*}{0.3528} & \multirow{3}{*}{0.5525} \\
\hline - Stent placement & $1(2.1 \%)$ & 0 & & \\
\hline - Baloon dilation then stent & 0 & $1(4.8 \%)$ & & \\
\hline Normal biliary system (2) & $1(2.1 \%)$ & $1(4.8 \%)$ & 0.3528 & 0.3528 \\
\hline
\end{tabular}


Standard free direct cannulation was done in 47 patients with success rate $64.4 \%$, the remaining 26 patients managed with indirect maneuvers with

\section{Table 2: - Success rate of ERCP}

\begin{tabular}{|l|c|c|c|c|}
\hline $\mathbf{7 3}$ cases & Gp-I $(\mathbf{n}: \mathbf{4 7})$ & \multicolumn{1}{c}{ Gp-II (n: 21) } & F & P \\
\hline Success rate & $47 \backslash 73(64.4 \%)$-Odd r:1.55 & $21 \backslash 26(80.8 \%)$ Odd r:1.23 & 0.1454 & 0.51 \\
\hline
\end{tabular}

The post-ERCP complications were noticed in 21 patients with complications rate of $28.8 \%$. PostERCP complications were higher in patients of indirect maneuvers versus patients of standard direct maneuver $(47.6 \%$ versus $23.4 \%)$. Post-ERCP successful cannulation of CBD in 21 cases with success rate $80.7 \%$ and total success rate was $94.4 \%$.

(Table 2)

Table 3: - Post-ERCP complications among the studied groups.

\begin{tabular}{|c|c|c|c|c|}
\hline 73 cases of done ERCP & $\begin{array}{c}\text { Gp-I } \\
(\mathrm{n}: 47)\end{array}$ & $\begin{array}{l}\text { Gp-II } \\
(\mathrm{n}: 21)\end{array}$ & $\mathbf{X}^{2}$ & $\mathbf{P}$ \\
\hline Abdominal pain & $3(6.3 \%)$ & $2(9.5 \%)$ & 0.210 & 0.6466 \\
\hline$(5-6.8 \%)$ & $2(4.3 \%)$ & $1(4.8 \%)$ & 0.924 & 0.3364 \\
\hline Contrast nephropathy $(1-1.3 \%)$ & $1(2.1 \%)$ & 0 & 0.453 & 0.2503 \\
\hline Pancreatitis & $2(4.3 \%)$ & $5(23.8 \%)$ & 6.0101 & $* 0.014225$ \\
\hline$(1-1.3 \%)$ & $1(2.1 \%)$ & 0 & 0.453 & 0.2503 \\
\hline Hematemesis $\quad(1-1.3 \%)$ & $1(2.1 \%)$ & 0 & 0.453 & 0.2503 \\
\hline $\begin{array}{l}\text { Haemodynamics instability and ICU } \\
\text { Admission } \quad(1-1.3 \%)\end{array}$ & $1(2.1 \%)$ & 0 & 0.453 & 0.2503 \\
\hline Perforation & 0 & 0 & & \\
\hline Death & 0 & 0 & & \\
\hline Total $(21-28.8 \%)$ & $11(23.4 \%)$ & $10(47.6 \%)$ & 3.9872 & $* 0.0458$ \\
\hline
\end{tabular}

\section{Discussion: -}

In the 1990s, new techniques such as DGT and TPS were introduced to overcome the difficult biliary cannulation.

From 73 patients subjected to ERCP in our endoscopy unit, during the between January 2016 to December 2017, 47 patients were managed with standard direct free cannulation maneuver (group-I), 21 patients managed with indirect biliary cannulation (group-II) and ERCP was failed in 5 cases.

With using of DGT, the rate of biliary cannulation was raised, this finding could be explained as the pancreatic guidewire can straighten both the PD and $\mathrm{BD}$ and occupying the PD, thus facilitating cannulation and reducing repeated pancreatic cannulation $^{7-8}$.

In our study standard free direct cannulation was done in 47 patients with success rate $64.4 \%$, the remaining 26 patients managed with indirect biliary cannulation (DGT andlor TPS) with successful pancreatitis recorded in 7 patients (9.6\%) with significant higher rate in patients of indirect maneuvers versus patients of standard direct maneuver (23.8\% versus $4.3 \%)$. (Table 3) 
This finding agrees with Freeman and Guda ${ }^{\mathbf{1 1}}$ who reported a post-ERCP complication rate of more than $20 \%$.

Complications were significantly higher in patients of indirect biliary cannulation maneuvers than patients of standard direct maneuver (47.6\% vs. $23.4 \%$ ).

Post-ERCP pancreatitis was recorded in 7 patients (9.6\%) with significant higher rate in patients of indirect biliary cannulation maneuvers than patients of standard direct free cannulation maneuver $(23.8 \%$ vs. $4.3 \%)$.

Similarly, Herreros et al. ${ }^{12}$ prospective randomized multicenter study, reported that, DGT post-ERCP pancreatitis is $17 \%$ versus $8 \%$ for standard direct free cannulation.

Young et al. ${ }^{\mathbf{1 3}}$ reported that post-ERCP pancreatitis with DGT was significantly higher than that with TPS (38.2\% vs $10.8 \%, P=0.011)$.

Patients of DGT needed more extensive manipulation and longer procedure time which may influence the development of post-ERCP pancreatitis ${ }^{\mathbf{1 3}}$.

We could conclude that indirect biliary cannulation as DGT andlor TPS is highly recommended to raise up the rate of ERCP success, but higher rate of mild post-ERCP complications is expected. Further study evaluating the prophylactic pancreatic duct stenting is highly recommended.

\section{References:}

1- Kawai K, Akasaka Y, Murakami K et al. (1992): Endoscopic sphincterotomy of the ampulla of Vater. Gastrointestinal Endoscopy, 20 (4) 148151.

2- Ramirez F, Dennert B and Sanowski R (1999): Success of repeat ERCP by the same endoscopist. Gastrointest Endosc., 49:58-61.

3- Masci E, Mariani A, Curioni $S$ and Testoni $P$ (2003): Risk factors for pancreatitis following endoscopic retrograde cholangiopancreatography: a meta-analysis. Endoscopy, 35:830-834.

4- Yasuda I and Itoi T (2013): Recent advances in endoscopic management of difficult bile duct stones, Digestive Endoscopy, 25 (4) 376-385.
5- Herreros A, Calleja J, Díaz G, Pertejo V, Espinel J, Cacho G, Jiménez J, Millán I, García F and Abreu L (2009): Double-guidewire technique for difficult bile duct cannulation: a multicenter randomized, controlled trial. Gastrointest Endosc., 70:700-709.

6- Min J, Jae C, Byung M, Jin H, Hyoung-Kyu R, Soon S, Joon K and Min K (2015): Wire-guided cannulation over a pancreatic stent versus double guidewire technique in patients with difficult biliary cannulation. BMC Gastroenterology, 15:150.

7- Gyökeres T, Duhl J, Varsányi M, Schwab R, Burai $M$ and Pap A (2003): Double guide wire placement for endoscopic pancreaticobiliary procedures. Endoscopy, 35:95-96.

8- Akashi R, Kiyozumi T, Jinnouchi K, Yoshida M, Adachi Y and Sagara K (2004): Pancreatic sphincter precutting to gain selective access to the common bile duct: a series of 172 patients. Endoscopy, 36:405-410.

9- Maeda S, Hayashi H, Hosokawa O, Dohden K, Hattori M, Morita $M$, Kidani $\mathbf{E}$, Ibe $\mathbf{N}$ and Tatsumi S (2003): Prospective randomized pilot trial of selective biliary cannulation using pancreatic guide-wire placement. Endoscopy, 35:721-724

10- Kahaleh M, Tokar J, Mullick T, Bickston SJ and Yeaton $P$ (2004): Prospective evaluation of pancreatic sphincterotomy as a precut technique for biliary cannulation. Clin Gastroenterol Hepatol., 2:971-977.

11- Freeman ML and Guda NM (2005): ERCP cannulation: a review of reported techniques. Gastrointest Endosc., 61:112-125.

12- Herreros de Tejada A, Calleja JL, Díaz G, Pertejo V, Espinel J, Cacho G, Jiménez J, Millán I, García F and Abreu L (2009): Double-guidewire technique for difficult bile duct cannulation: a multicenter randomized, controlled trial. Gastrointest Endosc., 70:700-709.

13- Young WY, Sang-Woo C, Woong CL, Sae HK, Anna $K$ and Young D (2009): Double guidewire technique vs transpancreatic precut sphincterotomy in difficult biliary cannulation .World $\mathrm{J}$ Gastroenterol., 7: 19(1): 108-114. 